\title{
Programa de habilidades interpessoais e direitos sexuais e reprodutivos para adolescentes: um relato de experiência
}

\author{
Shila Giardini Murta - UnivesidadedeBraślia, Braślia, Brasil \\ DaniloCrumind Ribèro- Pontifía UnivesidadeCatdica deGaiás \\ Isabda deOlivera Rosa - UniversidadedeBraślia, Braślia, Brasil \\ Jordana Calil Lqpes deMenezes - UniversidadedeBraślia, Braślia, Brasil \\ Marcella Regina Silva Rièro- Pontifía UnivesidadeCatdica deGaás \\ Ohary deSausa Borges - Pontifía UniversidadeCatdica deGciás \\ Silvia Guimarães dePaulo- Pontifía UnivesidadeCatdica deGdás \\ Vecônica deOlivèra - Pontifía UnivesidadeCatdica deGciás \\ Vidtor HugodeMiranda - Pontifíaa UnivesidadeCatdica deGciás \\ Almir Ded Prette- UnivesidadeFeleral deSãoCanlos, SãoPaulo, Brasil \\ ZildaA. P. Dd Prette- UniversidadeFederal deSãoCarlos, SãoPaulo, Brasil
}

\begin{abstract}
Resumo
Este artigo relata a experiência de aplicação de um programa de promoção de habilidades interpessoais e direitos sexuais e reprodutivos para adolescentes. Participaram 93 adolescentes, de ambos os sexos, estudantes de uma escola pública. A intervenção foi do tipo prevenção universal conduzida na escola, em 15 sessões semanais, agrupadas em três módulos: (I) identidade e resiliência, (II) habilidades sociais e manejo das emoções e (III) sexualidade, gênero e direitos sexuais e reprodutivos. O s resultados apontaram a adequação do uso de procedimentos vivenciais e de seu embasamento na cultura adolescente e a necessidade de alterar a ordem das sessões em versões futuras dessa intervenção. São discutidas direções para o replanejamento do programa.

Palavas dhave Prevenção; Habilidades sociais; Habilidades de vida; Gênero; Adolescência.
\end{abstract}

Program of interpersonal skills and reproductive and sexual rights for adolescents: an experience report

\begin{abstract}
This paper describes the experience of applying a program of interpersonal skills and sexual and reproductive rights for adolescents. The participants were 93 adolescents, male and female, students in a public school. The intervention was universal prevention type and it was implemented at school in 15 weekly sessions organized in three thematic blocks: (I) identity and resilience; (II) social skills and emotions management; and (III) sexuality, gender and sexual and reproductive rights. The results showed the adequacy of using experienced procedures, their basis in adolescent culture the need for changing the sessions order in future versions of this program. Directions for the program redesign are discussed.

Kegwards Prevention; Social skills; Life skills; G ender; Adolescence.

Programa de habilidades interpersonales y derechos sexuales y reproductivos para adolescentes: un relato de experiencia

Resumen

Este artículo relata la experiencia de aplicación de un programa de promoción de habilidades interpersonales y derechos sexuales y reproductivos para adolescentes. Participaron 93 adolescentes, de ambos sexos, estudiantes de una escuela pública. La intervención fue del tipo prevención universal y fue conducida en la escuela, en 15 sesiones, semanales, agrupadas en tres módulos: (I) identidad y resiliencia, (II) habilidades sociales y manejo de las emociones y (III) sexualidad, género y derechos sexuales y reproductivos. Los resultados señalaron la adecuación del uso de procedimientos vivenciales y de su embasamiento en la cultura adolescente y la necesidad de alterar el orden de las sesiones en versiones futuras de esa intervención. Son discutidas direcciones para el replaneamiento del programa.

Palabrasdave Prevención; Habilidades sociales; Habilidades de vida; Género; Adolescencia.
\end{abstract}

0 uso de tecnologias em programas de ensino de habilidades de vida e habilidades sociais tem sido extensamente explorado, tanto no país (Bolsoni-Silva \& cols., 2006; Del Prette \& D el Prette, 2005; Lopes, 2009; Minto, Pedro, Cunha Neto, Bugliani \& Gorayeb, 2006) quanto no exterior (Epstein, G riffin \& Botvin, 2002; Gresham, 2009; World Health Organization, 1997), como parte integrante de programas de prevenção a problemas emocionais e comportamentais em crianças e adolescentes. Além de se mostrarem efetivos
(Gresham, 2009; Murta, 2007), esses programas requerem poucos recursos em sua aplicação (são economicamente viáveis), podem ser usados em grupo (podem ter aplicação em serviços educacionais, comunitários e de saúde, com fácil inserção nas políticas públicas), seus efeitos tendem a se manter no tempo e seus benefícios podem se expandir para várias áreas do funcionamento psicossocial do indivíduo (são generalizáveis). 
O relato de uma experiëncia de promoçäo de habilidades interpessoais e direitos sexuais e reprodutivos em adolescentes é 0 foco do presente artigo. Trata-se de uma intervenção cujas bases foram tomadas de empréstimo de programas para adolescentes baseados no ensino de habilidades de vida (Minto \& cols., 2006; Murta \& cols., 2009; Murta, D el Prette \& Del Prette, 2010) e habilidades sociais (Bolsoni-Silva \& cols., 2006; Del Prette \& Del Prette, 2001; Gresham, 2009). O termo habilidades de vida é aplicado a um amplo conjunto de comportamentos envolvidos no enfrentamento de demandas da vida cotidiana, onde se incluem tomada de decisão, pensamento crítico, pensamento criativo, resolução de problemas, comunicação assertiva, manejo de estresse e manejo das emoções (World Health Organization, 1997). O termo habilidades sociais, por sua vez, constitui uma categoria conceitual mais delimitada, referindo-se aos comportamentos sociais que contribuem para a competência social e para a qualidade dessa relação, definidos em articulação com 0 conceito de competência social (Del Prette \& Del Prette, 2001; 2005). As classes de habilidades sociais incluem, por exemplo, assertividade, empatia, resolução de problemas interpessoais e comunicação, que podem ser utilizadas e combinadas em um desempenho mais amplo e sujeito a critérios de avaliação em termos de competência social.

Conforme apontado e evidenciado na literatura (Murta \& cols., 2010), os programas de habilidades de vida e habilidades sociais não foram ainda testados como estratégias de promoção de direitos sexuais e reprodutivos entre jovens e adolescentes, razão pela qual se tornam necessários o desenvolvimento, a testagem e 0 refinamento de procedimentos. Considerou-se que 0 ensino dessas habilidades poderia contribuir para 0 desenvolvimento de atitudes mais flexíveis para com os papéis de gênero, favorecendo 0 desenvolvimento de modos de se relacionar mais respeitosos em relação ao próprio direito, ao direito do outro e à diversidade humana. Essas habilidades podem ter impacto direto na tomada de decisão, solução de problemas e comunicação na adolescência, em situações que demandam negociação e exercício de direitos, como as que se relacionam ao início da vida sexual, à anticoncepção e ao manejo das diferenças interpessoais em relações de namoro.

$\mathrm{Na}$ adolescência, 0 desenvolvimento de tecnologias psicossociais para a promoção dos direitos sexuais e reprodutivos pode favorecer 0 empoderamento de rapazes e moças e contribuir para a prevenção de danos à saúde e ao desenvolvimento nesta etapa da vida, como a gravidez precoce (Aquino \& cols., 2003), as doenças sexualmente transmissíveis
(Asinelli-Luz \& Fernandes Jr., 2008) e a violência no namoro (Aldrighi, 2004; Matos, Machado, Caridade \& Silva, 2006; Schwartz, Magee, Griffin \& Dupuis, 2004). Independente do momento no ciclo de vida, diversos e severos são os danos à saúde derivados da usurpação do direito de vivenciar com autonomia a sexualidade e a reprodução: a mutilação da genitália feminina, a escolha do cônjuge feita por terceiros (estes, principalmente em parte das culturas africanas e orientais) (Bandeira, 2009), a homofobia (Borges \& Meyer, 2008), a maternidade ou paternidade indesejada, a violência de gênero (Lima, Büchele \& Clímaco, 2008), a violência pelo parceiro íntimo (Schraiber, D'Oliveira \& França Jr., 2005), os transtornos depressivos e de ansiedade em mulheres (Andrade, Viana \& Silveira, 2006), 0 aborto em condições de risco, a AIDS e as doenças sexualmente transmissíveis (Nogueira, Saavedra \& Costa, 2008).

Para grande parte desses problemas, as primeiras vítimas das violações de direitos sexuais e reprodutivos são as mulheres e os homossexuais. Portanto, crenças e práticas culturais sexistas e heterossexistas constituem as bases para 0 abuso dos direitos sexuais e reprodutivos. $\mathrm{O}$ enfraquecimento dessas crenças e práticas deve estar, sobretudo por razões éticas, entre as metas das tecnologias psicossociais construídas pela ciência psicológica. Ademais, contribuições da psicologia nesse sentido poderiam fortalecer esforços de natureza interdisciplinar e intersetorial (por exemplo, Junqueira, 2009; Ribeiro \& Quadrado, 2008), relativos à implementação de políticas públicas em gênero, educação e direitos humanos, nesta última década. D entre estas, destacam-se o Plano Nacional de Políticas para as Mulheres, que propõe diferentes ações de promoção da equidade de gênero (Secretaria Especial de Políticas para as Mulheres, 2005) e 0 Programa Brasil sem Homofobia, que busca reduzir práticas de violência e hostilidade contra pessoas com orientação sexual homossexual ou bissexual (Ministério da Saúde, 2004).

Ainda que o exercício dos direitos sexuais e reprodutivos constitua fator de proteção à saúde sexual, reprodutiva e mental, grandes embates sociais têm havido no Brasil, nem sempre com sucesso, com vistas à sua proteção (Mattar, 2008). A vivência desses direitos contraria costumes e crenças da cultura, frequentemente disseminados em contextos de grande impacto, como a legislação (ao não reconhecer, por exemplo, o direito da mulher à escolha da interrupção da gestação de feto anencéfalo), a mídia (ao divulgar, por exemplo, músicas de conteúdo sexista), a religião (ao doutrinar, por exemplo, para o não uso de métodos anticonceptivos) e a escola (ao negligenciar, por 
exemplo, o combate à homofobia) (Lionço \& Diniz, 2009; Louro, 2007).

Esses obstáculos culturais podem explicar por que é relativamente escasso na literatura, nacional e internacional, 0 desenvolvimento de tecnologias psicossociais para promoção de direitos sexuais e reprodutivos em adolescentes (Pocahy \& Nardi, 2007), quando comparado a outras áreas de produção científica em psicologia preventiva na infância e adolescência (Murta, 2007). Isso considerado, 0 presente estudo teve por objetivo geral relatar uma experiência de desenvolvimento e aplicação de procedimentos em uma intervenção focada na promoção de direitos sexuais e reprodutivos, habilidades de vida e interpessoais. Dado ser esta uma articulação nova entre áreas de conhecimento, esta experiência foi tomada como passo inicial na construção do programa, a partir do qual seriam viabilizados 0 refinamento de procedimentos e a avaliação sistemática em versões futuras.

\section{Relato de experiência}

\section{Participantes}

Participaram 93 adolescentes, sendo 53 do sexo feminino e 40 do sexo masculino, com idades entre 12 e 17 anos, alunos do $8^{0}$ e 90 anos do ensino fundamental de uma escola pública de $\mathrm{G}$ oiânia. Quanto à escolaridade dos pais, $45,7 \%$ deles cursaram nível médio, 22,3\% cursaram ensino fundamental, 19,1\% cursaram nível superior e $9,6 \%$ eram analfabetos. A configuração familiar incluía residência com ambos os pais $(42,6 \%)$, apenas com um dos pais $(36,2 \%)$, com tios $(5,3 \%)$, com avós $(4,3 \%)$, com avó e mãe $(4,3 \%)$, com amigos $(2,1 \%)$, conhecido $(1,1 \%)$, cônjuge $(1,1 \%)$ ou família extensa (1,1\%). D entre outras características, destacam-se: (a) a maioria dos participantes $(73,4 \%)$ informou não praticar atividades extracurriculares (como, por exemplo, aprendizado de línguas e música); (b) grande parte trabalhava para ajudar nas despesas da família $(69,1 \%)$ e ajudava a cuidar dos irmãos mais novos (54,3\%); (c) 20,2\% relatou fazer uso de álcool e $1,1 \%$ fazia uso de fumo; (d) a quase totalidade $(97,9 \%)$ não fazia uso de medicação controlada e (e) apenas dois jovens afirmaram já terem engravidado e engravidado a namorada.

\section{Procedimento deintervençãoecdéa dedadbs}

O programa ocorreu no horário das aulas, com duas turmas de oitavo ano e duas turmas de nono ano, cada uma com aproximadamente 25 alunos. A intervenção foi do tipo prevenção universal (Munoz, Mrazek \& Haggerty, 1996), por incluir todos os alunos da classe, ao invés de incluir somente aqueles expostos a riscos (exemplo, os que tinham crenças heterossexistas ou haviam testemunhado violência conjugal entre os pais) ou com manifestações iniciais de transtornos emocionais ou comportamentais.

Compreendeu 15 sessões, semanais (à exceção de algumas que foram quinzenais por causa de eventos ocorridos na escola), de 90 minutos de duração, em duas aulas consecutivas da disciplina de Artes. Foi construído em três módulos: 0 primeiro compreendeu as seis primeiras sessões e abordou a "Identidade e a Resiliência"; 0 segundo, da sétima à nona sessão, enfatizou o desenvolvimento de "Habilidades Sociais e o Manejo das Emoções"; e o último, da décima à décima quinta sessão, tratou de "G ênero, Sexualidade e Direitos Sexuais e Reprodutivos". As sessões foram planejadas e conduzidas num formato psicoeducativo, com objetivos e técnicas previamente planejadas. Uma síntese dos temas e habilidades desenvolvidas em cada sessão está disponível na Tabela 1. A condução das sessões foi feita em dupla ou trio, algumas compostas apenas por facilitadoras e outras por facilitadores e facilitadoras. Foi utilizado um diário de campo, onde foram registrados eventos relevantes ocorridos em cada sessão, sobre a aceitabilidade do programa.

Este projeto de pesquisa foi aprovado pelo Comitê de Ética em Pesquisa da Pontifícia Universidade Católica de Goiás (Processo 0005.0.168.000-08). Diversos cuidados éticos foram tomados antes (convite para participação e esclarecimentos), durante (supervisão constante para maximizar qualidade da intervenção e prevenir riscos) e depois da coleta de dados (devolução de resultados à escola e Secretaria de Educação de G oiás), conforme previsto na Resolução CFP 016/2000 e Resolução 096/ 96 do Conselho Nacional de Saúde.

Tabela 1. Temas e habilidades desenvolvidas por sessão

\begin{tabular}{lll}
\hline Sessão & Tema & Habilidades de vida \\
\hline 1 & $\begin{array}{l}\text { Como eu penso que homens e mulheres devem se } \\
\text { relacionar? }\end{array}$ & Autoconhecimento e relacionamento interpessoal \\
2 & $\begin{array}{l}\text { Que homem/ mulher quero ser? Que recursos eu tenho } \\
\text { para crescer? }\end{array}$ & Autoconhecimento e resolução de problemas \\
3 & Meus pontos fortes. Avaliação inicial. & Autoconhecimento \\
\hline
\end{tabular}


Tabela 1. Temas e habilidades desenvolvidas por sessäo

\begin{tabular}{|c|c|c|}
\hline Sessão & Tema & Habilidades de vida \\
\hline 4 & $\begin{array}{l}\text { Diversidade e diferença: Como eu sou? Como meu colega } \\
\text { é? }\end{array}$ & $\begin{array}{l}\text { Autoconhecimento, pensamento criativo, pensamento } \\
\text { crítico, empatia e relacionamento interpessoal }\end{array}$ \\
\hline 5 & Meu futuro começa hoje & $\begin{array}{l}\text { Autoconhecimento, lidar com o estresse e resolução de } \\
\text { problemas }\end{array}$ \\
\hline 6 & $\begin{array}{l}\text { Violência no namoro, violência contra a mulher e recursos } \\
\text { de autoproteção }\end{array}$ & $\begin{array}{l}\text { Relacionamento interpessoal, empatia, lidar com } 0 \\
\text { estresse e resolução de problemas }\end{array}$ \\
\hline 7 & $\begin{array}{l}\text { Modos construtivos e destrutivos de expressar e lidar com } \\
\text { as emoções }\end{array}$ & $\begin{array}{l}\text { Lidar com o estresse, lidar com as emoções, } \\
\text { comunicação eficaz, empatia, resolução de problemas e } \\
\text { tomada de decisão. }\end{array}$ \\
\hline 8 & $\begin{array}{l}\text { Enfrentamento à violência no cotidiano: as violências } \\
\text { sofridas e as violências praticadas }\end{array}$ & $\begin{array}{l}\text { Comunicação eficaz, empatia, resolução de problemas e } \\
\text { recursos para proteção }\end{array}$ \\
\hline 9 & Reescrevendo as relações: da violência à assertividade & Comunicação eficaz, empatia e resolução de problemas \\
\hline 10 & Repensando a masculinidade e feminilidade & Pensamento crítico e relacionamento interpessoal \\
\hline 11 & $\begin{array}{l}\text { Aprendendo a tomar decisões e resolvendo problemas sem } \\
\text { violência }\end{array}$ & $\begin{array}{l}\text { Pensamento crítico, pensamento criativo, tomada de } \\
\text { decisão e resolução de problemas }\end{array}$ \\
\hline 12 & Adolescência e sexualidade & $\begin{array}{l}\text { Pensamento crítico, tomada de decisão e resolução de } \\
\text { problemas }\end{array}$ \\
\hline 13 & $\begin{array}{l}\text { Lidando com pressões e conhecendo os direitos sexuais e } \\
\text { reprodutivos }\end{array}$ & $\begin{array}{l}\text { Pensamento crítico, tomada de decisão, resolução de } \\
\text { problemas, comunicação eficaz, lidar com as emoções e } \\
\text { relacionamento interpessoal }\end{array}$ \\
\hline 14 & Avaliação final & Autoconhecimento \\
\hline 15 & Prevenção de recaída & Autoconhecimento \\
\hline
\end{tabular}

\section{Resultados e discussão}

Neste estudo, o resultado será apresentado junto com a discussão, para facilitar a análise dos aspectos de procedimento que serão apresentados em forma mais detalhada, sessão a sessão, conforme se segue. Assim, a cada sessão, aspectos pertinentes à análise do programa serão discutidos.

Na primeira sessão, foi feita a apresentação dos objetivos do programa, dos aspectos éticos da pesquisa e da equipe. Foi proposto o Jogo da Verdade para identificar as crenças que os adolescentes tinham sobre os papéis de gênero, os direitos sexuais e reprodutivos e a adolescência. O Jogo da Verdade continha uma lista de sentenças incompletas, com temas relativos a papéis de gênero, sexualidade e projeto de vida. Uma caneta era virada no chão e aquele para quem ela apontava devia escolher um número, que era correspondente a uma sentença, que deveria ser completada pelo participante. As respostas dos alunos a estas questões mostraram, em alguns dos relatos, a presença de papéis de gênero tradicionais (se meu marido quiser que eu tenha filhos, mesmo que eu não queira, eu... dou), 0 modelo de família heteronormativa (ex.: acho que os homens não deveriam... casar com homens), risco de violência de gênero (ex.: se um dia meu/minha namorado/a fizer gozação comigo, me humilhar e criticar na frente dos outros eu... dau uma tijdada nda) e conteúdos homofóbicos (ex.: se meu irmão tiver um amigo homossexual eu... nãovaugostar).
$\mathrm{Na}$ segunda sessão, os objetivos foram desenvolver autoconhecimento e resolução de problemas. Os adolescentes foram convidados a realizar um desenho coletivo sobre seus sonhos como homem/mulher. A técnica foi feita em pequenos grupos em círculo, em que cada adolescente recebia uma folha em branco e desenhava por um minuto algo relacionado a seus sonhos, desejos e projetos como homem/mulher. Após um minuto, a folha rodava e passava para o colega da direita, que continuava 0 desenho, e assim sucessivamente, até que todos tivessem completado o desenho. Ao final, a produção coletiva do grupo era mostrada para a sala toda e se discutia os sonhos e valores expressos nos desenhos, buscando similaridades e diferenças entre eles. Em seguida, foram convidados a jogar o Jogo do Balão (Murta, 2008), a fim de se discutir o enfrentamento às adversidades e os fatores de proteção vivenciados por eles. Os adolescentes foram instruídos a se posicionar em um círculo e cada um deles deveria jogar o balão para 0 colega da direita. Aquele que não pegasse 0 balão na sua vez era excluído do jogo. Enquanto 0 balão corria a roda, ocorriam jogadas mais difíceis, que supunham maior deslocamento, esforço e iniciativa por parte do participante para pegar a bola na sua vez. Esta metáfora (pegar balões difíceis) foi usada para explorar os fatores de proteção e habilidades de enfrentamento, isto é, o que tinham que fazer no jogo para pegar 0 balão e relacionar isto ao que faziam na vida para enfrentar as adversidades. Foram encorajados a falar 
sobre suas qualidades que os ajudavam a lidar com as situações difíceis e a localizar, na família, na escola e na comunidade, pessoas e serviços com quem podiam contar. Foi utilizado o formulário Que Recursos eu Tenho para Crescer (Murta, 2008), contendo três círculos, um dentro do outro, cujo menor tinha escrita a palavra Eu, o segundo continha Família, Amigos Escda eGuupos e 0 terceiro continha os nomes Cidade, País e Munda Os adolescentes foram instruídos a refletir e escrever em cada círculo os seus recursos para crescer e, sem seguida, apresentá-los para a sala. Discutiu-se com os participantes a busca de recursos como via para a superação de adversidades (Lynch, Geller \& Schmidt, 2004). Como tarefa, foi proposto que eles conversassem durante a semana com um amigo sobre o que gostariam de ser no futuro. Nessa sessão, a atividade de Jogo do Balão foi a que provocou maior adesão e satisfação por parte dos adolescentes, conforme constatado ao final, quando foram questionados sobre o que haviam gostado ou não no encontro, conforme indica o relato: "A atividade foi boa, mostrou que a gente pode mudar e fazer diferente". Esse procedimento, de avaliação de reação à sessão, foi repetido ao final das sessões seguintes.

Salienta-se, todavia, que a autorrevelação dos adolescentes em voz alta foi, muitas vezes, inibida por brincadeiras dos pares, o que acabava por punir a participação. Assim, o uso de medidas verbais orais ao fim da sessão para avaliar satisfação com a intervenção se mostrou parcialmente comprometido. E possível que os participantes tenham se sentido inibidos diante de um grande número de colegas (25 adolescentes por grupo). De fato, o número de adolescentes no grupo constituiu, desde as primeiras sessões, 0 maior dificultador na implementação do programa. Isso competia com o comportamento de seguir regras, por parte dos adolescentes, o que demandou da equipe habilidades de manejo de comportamentos adequados e inadequados dos alunos. Além disso, foi observado que a atenção individualizada aos adolescentes, como chamar pelo nome e demonstrar interesse por suas habilidades (como desenhar), favoreciam a aproximação entre eles e os facilitadores, como já identificado por outros autores (Sale, Bellamy, Springer \& Wang, 2008). Isso contribuiu para melhorar a adesão, no decorrer das sessões seguintes. Por isso, a partir dessa sessão, foram incorporados no diário de campo registros sobre a ocorrência de comportamentos indicativos da construção de vínculo entre adolescentes e facilitadores (ex.: solicitar apoio ao facilitador).

$\mathrm{Na}$ terceira sessão, foi feita a avaliação de préteste, com aplicação de sociometria e uma escala para avaliação de habilidades sociais (Del Prette \& Del
Prette, 2009a). Na décima quarta sessão, esses instrumentos foram reaplicados.

Os objetivos da quarta sessão foram desenvolver autoconhecimento, pensamento criativo, pensamento crítico, empatia e relacionamento interpessoal. Ao iniciar a sessão, os adolescentes foram solicitados a falar sobre seus "ídolos", figuras públicas ou não, por quem tinham admiração. Em seguida, a discussão buscou explorar os riscos enfrentados pelo ídolo, os obstáculos que superou e 0 que 0 adolescente admirava naquela pessoa. Em seguida, foi lido e discutido o texto "E se no mundo não existissem diferenças", de autoria da equipe de pesquisa, que abordava em linguagem poética a riqueza existente na diversidade e na diferença. Foram encorajados a falar o que pensavam sobre as diferenças entre as pessoas (ex.: religião, raça, sexualidade, gênero, preferências), 0 valor das diferenças, 0 direito a ser diferente e o preconceito e a tolerância ao diferente. Após, foi feita a atividade "Meu Perfil no Orkut". Cada participante preencheu por escrito o seu perfil (ex.: músicas e filmes preferidos, qualidades desejáveis em um parceiro/a etc.) e em seguida o discutiu com um colega, em duplas. Ao final, cada adolescente apresentou o seu colega, destacando as semelhanças e diferenças observadas entre eles. Essa foi uma das atividades do primeiro módulo na qual os adolescentes mais se envolveram e sobre a qual relataram satisfação, possivelmente por ter sido uma atividade inserida na cultura do adolescente, o que tem sido apontado como relevante em programas preventivos nesse estágio da vida (Goldston \& cols., 2008; Harper, 2007). A sessão foi concluída com a tarefa de entrevistar ao longo da semana uma pessoa idosa para avaliar as diferenças entre gerações em aspectos como namoro, diversão, escola, trabalho na adolescência, dentre outros.

O módulo "Identidade e Resiliência" foi encerrado na quinta sessão, quando os participantes foram informados sobre o que é resiliência e como ela pode ser promovida, por meio da exposição dialogada, psicoeducação e atividade de colagem. A sessão almejou desenvolver as habilidades de autoconhecimento, lidar com o estresse e resolução de problemas. Teve início com a discussão da tarefa de casa, o que se repetiu para todas as sessões que foram precedidas por alguma tarefa. Isso nem sempre ocorreu devido a flutuações na adesão dos adolescentes à tarefa de casa. Em seguida, foram instruídos a se organizarem em subgrupos e localizarem em revistas as figuras que representassem a resiliência, como exemplos de fatores de proteção ou pessoas/ experiências de superação de adversidades. Fizeram uma colagem e em seguida discutiram o que haviam produzido. Na sequência, foi proposta a atividade "Viagem ao Túnel do Tempo". 
Foram instruidos a dividir uma folha de papel em tres colunas: "Uma Visita ao Passado", "Um Pulo no Futuro" e "De Volta ao Presente". Expressaram em palavras ou desenhos como se viam no passado e como se viam no futuro. Durante a apresentação dos projetos de futuro, foi utilizada a técnica de solução de problemas. Os participantes foram encorajados a discutir os recursos, estratégias e passos necessários para que seus projetos se concretizassem. A tarefa de casa foi escrever em um formulário próprio um passo que percebiam como necessário para alcançar os sonhos de futuro discutidos naquela sessão. A técnica de solução de problemas foi vista como positiva por um dos participantes: "Gostei de aprender que diante dos problemas temos várias alternativas e devemos escolher a melhor".

O módulo "Habilidades Sociais e Manejo das Emoções" veio a seguir, com três sessões. A sexta sessão teve por objetivos promover melhoria nas relações interpessoais, estimular a empatia, identificar comportamentos de risco para a violência no namoro e recursos comunitários para proteção à violência contra a mulher e 0 adolescente. Foi utilizado um recorte de jornal que descrevia um episódio de violência pelo parceiro íntimo que resultou em morte da mulher e de uma filha do casal, amplamente noticiada pelos jornais da cidade naquela semana. Foi usada a técnica de Histórias Incompletas. Os alunos foram solicitados a criar dois textos: a primeira história com o final já dado (o desfecho trágico do jornal), recriando o começo e 0 desenrolar da relação afetiva entre os cônjuges; e a segunda história com o começo dado, quando dois adolescentes começam a namorar e há um primeiro desentendimento entre eles, e os alunos foram solicitados a criar 0 final da história. Durante a discussão das histórias, foi dada ênfase nas emoções geradas pelas crises, nas vantagens e desvantagens de estratégias de resolução de conflitos baseadas na violência, no uso da comunicação assertiva e na busca da rede de apoio social (amigos, familiares ou serviços em saúde mental) quando em crise. Ao final, realizouse a psicoeducação, com uso de material informativo escrito e discussão dos sinais de violência no namoro (ex.: ciúme excessivo), as formas de violência contra a mulher (física, psicológica, moral, sexual e patrimonial) e contra a criança e 0 adolescente, segundo a Lei Maria da Penha e o Estatuto da Criança e do Adolescente, respectivamente. Por fim, receberam uma lista com serviços existentes na cidade, localizados, sobretudo, no bairro, seguidos de seus respectivos endereços e telefones, que pudessem consistir em fatores de proteção comunitários, tais como Centro de Atenção Psicossocial à Criança e Adolescente, Conselho Tutelar, Escola de Artes, Delegacia da Mulher, dentre outros. A tarefa desta semana toi escrever em formulário próprio um passo que deram na semana para realizar suas metas de futuro, desde pensar sobre, planejar, buscar informação ou efetivamente fazer algo no sentido de se aproximar delas. $\mathrm{Na}$ avaliação final, 0 tema da comunicação entre os parceiros foi destacado por um dos participantes como válido: “É bom saber que em muitas situações é melhor conversar do que apelar e agredir". Porém, vários participantes acharam enfadonha a estratégia de criar textos a partir do recorte de jornal e argumentaram que a 0 tema da notícia estava já muito "batido" pela mídia local. Q uando indagados sobre suas sugestões para as sessões seguintes, algumas delas foram: "Ir para a quadra", "Fazer coisas diferentes", "Ir para a sala de computação", "Fazer mais atividades com desenho", "Passar um filme bem legal", "Colocar música para a gente ouvir", "Fazer alguma coisa com bola", "Fazer festa na última sessão". Essas sugestões influenciaram na seleção das técnicas, materiais e procedimentos usados posteriormente, como a redução em procedimentos que lembravam a rotina da escola (como a produção de textos) e o uso de técnicas arteterapêuticas, vivenciais $\mathrm{e}$ inseridas na cultura adolescente.

A sétima sessão teve por objetivo discutir a identificação e manejo de emoções desagradáveis, como ansiedade, raiva e tristeza, e o uso da comunicação assertiva para redução do risco para violência, depressão, abuso de drogas, gravidez precoce e suicídio. Inicialmente, a técnica usada foi a confecção de uma máscara que expressasse 0 modo habitual de expressar emoções (Murta, 2008). A produção dos adolescentes foi discutida, salientando-se os diferentes modos de expressar sentimentos, seus ganhos e custos para a saúde mental e para os relacionamentos. Durante a discussão, ênfase foi dada às vantagens de expressar sentimentos sem "se machucar" e sem "machucar o outro", pedir ajuda para pessoas de confiança e controlar a impulsividade de modo a reduzir risco de abuso de drogas e sexo sem proteção, em situação de crise e estresse. A tarefa de casa foi escolher uma situação para praticar a expressão de sentimentos, sem "se machucar" e sem "machucar os outros". O tema da assertividade pareceu ser novo para os alunos, até então, como sugere o relato ao fim dessa sessão: "A prendi sobre assertividade".

$\mathrm{Na}$ oitava sessão, foram discutidas as microviolências presentes no cotidiano dos adolescentes (as recebidas, as praticadas e os modos de enfrentamento) e a comunicação assertiva como alternativa de resolução de conflitos. Para abordar a violência no cotidiano, foi usada a música " $\mathrm{O}$ homem na estrada”, do grupo Racionais M'cs. Logo após 
ouvirem a música, foram convidados a preencher um formulário de automonitoramento contendo as situações de violência vivenciadas, como receptores ou autores, os sentimentos experimentados e o que faziam para lidar com essas situações, em ambos os papéis, de vítimas e de perpetuadores. Em seguida, foram apresentados os direitos humanos básicos (Del Prette \& Del Prette, 2001) e foi enfatizado que toda a comunidade escolar, alunos, professores e familiares, possuem direitos. Por fim, a comunicação assertiva foi apresentada por meio da técnica de modelação. Foram expostos vídeos de curta duração do Sistema Multimídia de Habilidades Sociais para Crianças, contendo episódios de interações entre crianças em escolas, com desfechos passivo, agressivo e assertivo (Del Prette \& Del Prette, 2006; Lopes, 2009). Foram selecionados apenas os vídeos envolvendo as habilidades de recusar pedido, pedir mudança de comportamento e resistir à pressão do grupo. Em seguida, em pequenos grupos, foi feito ensaio comportamental. Os alunos foram convidados a criar e dramatizar cenas com desempenhos assertivos. Foram salientados os efeitos negativos da comunicação passiva e agressiva, para a pessoa que emite e a que recebe a comunicação, e nas vantagens da comunicação assertiva, para todos os envolvidos na interação. A atividade de dramatização foi a mais apreciada pelos participantes no segundo módulo da intervenção. Um dos relatos nessa sessão indicou uma sensibilização para regras e limites na relação com o outro, conforme o seguinte relato sobre ganhos obtidos na sessão: "Aprender a respeitar os colegas".

A partir da nona sessão, teve início o módulo "Gênero, Sexualidade e Direitos Sexuais e Reprodutivos". Diferente dos módulos anteriores, em que partes do programa produziram boa adesão e outras partes, uma menor adesão, todas as sessões desse módulo resultaram em grande interesse por parte dos adolescentes, 0 que ficou evidente pelos comportamentos de seguir as instruções dos facilitadores, olhar atentamente, concluir as tarefas solicitadas e fazer perguntas. Isso sugere ser este um tema percebido como muito relevante na vida do adolescente, sobre 0 qual eles têm poucas oportunidades de discussão, à exceção de aulas centradas nos aspectos biológicos da sexualidade, como extensamente discutido por Louro (2007) e Lionço e Diniz (2009). As sessões foram construídas com o intuito de gerar pensamento crítico acerca dos papéis de gênero, da diversidade sexual e dos aspectos sociais e afetivos da sexualidade. Foram feitas ligações entre as sessões anteriores e estas, sempre que oportuno, a fim de fortalecer 0 empoderamento dos adolescentes e aumentar suas competências (como autoconhecimento, tomada de decisão, resolução de problemas e empatia) e estratégias de enfrentamento à possíveis situações de risco para homofobia, sexismo, violência na relação de namoro e gravidez precoce.

A nona sessão, "Repensando a masculinidade e a feminilidade", teve como objetivos desenvolver 0 pensamento crítico e discutir sobre papel de gênero e orientações sexuais. Nesse sentido, foi apresentado 0 filme "Acorda Raimundo... Acorda!" (dirigido por Alves, lançado em 1990) e posteriormente realizada uma discussão, em que os participantes relataram o que conseguiram retirar do filme e levar para suas vidas. Em seguida foi realizado um jogo para distinguir mito e realidade a respeito do tema "ser homem ou mulher", que consistia nos participantes se locomoverem em direção aos cartazes dispostos na sala, com as inscrições "concordo", "discordo" e "tenho dúvida", quando fossem lidas as frases com os mitos atribuídos a masculinidade, feminilidade, gênero, sexualidade e orientações sexuais (Serrão \& Baleeiro, 1999). Quando acomodados diante dos cartazes escolhidos, 0 facilitador indagava por que concordavam, ou discordavam ou que dúvida tinham. Ao fim da sessão, foi distribuído um folheto com informações sobre os mitos e discutidas as curiosidades históricas e culturais sobre os papéis de gênero. Para reflexão final, foi lida a história do menino das meias vermelhas, acerca da convivência com o diferente (autor desconhecido) e solicitado que os participantes relacionassem a história com o tema do dia. A tarefa de casa foi levar para a próxima sessão músicas sobre como o homem trata a mulher ou como a mulher trata o homem. As informações dadas na sessão foram avaliadas como positivas por alguns dos participantes, chegando a sensibilizar para 0 respeito à diversidade sexual: "G ostei do tema dos mitos e verdades sobre gênero e sexualidade. As informações dadas foram esclarecedoras", "Aprender a não ter preconceitos", "Às vezes eu tinha um ponto de vista e agora tenho outro". Contudo, isso não foi verdadeiro para todos os participantes, como mostra este relato com conteúdo homofóbico: "Não gostei, porque falou muita coisa que não gosto, [falou da] homossexualidade".

A décima sessão objetivou desenvolver pensamento crítico, desenvolver pensamento criativo, tomada de decisão e resolução de problemas. Nessa sessão foi realizado o Jogo da História Inacabada. Para esse jogo, a turma foi dividida em oito grupos e cada grupo teve a tarefa de dar um final oral para as pequenas histórias lidas. Todas as histórias contemplavam temas relacionados ao gênero, sexualidade e uso de drogas e apresentavam demandas para a tomada de decisão e resolução de problemas. Em seguida, foi realizada uma discussão sobre os finais 
construídos, considerando-se ganhos e custos e efeitos possíveis das decisões. Como tarefa, foi solicitado aos adolescentes que pesquisassem cenas de TV que abordassem os temas tratados. A avaliação de reação à sessão mostrou que os procedimentos usados estimularam 0 pensamento consequencial, conforme mostram os relatos de alguns adolescentes que se manifestaram: "Ter as decisões certas", "Pensar nas consequências", "Pensar antes de agir".

Na décima primeira sessão, foram trabalhadas as habilidades de vida de pensamento crítico e tomada de decisão. Foi realizada a técnica do "O uvi dizer que" (Serrão \& Baleeiro, 1999), na qual os adolescentes escreveram em cartolinas o que sabiam ou haviam ouvido dizer sobre virgindade, primeira relação sexual, orgasmo, gravidez na adolescência, masturbação, anticoncepção, homossexualidade, ato sexual, DST/AIDS e aborto. Logo após, ocorreu uma discussão sobre as respostas fornecidas pelos participantes, as vantagens e desvantagens de comportamentos de risco à saúde e foram dadas novas informações sobre os temas, sempre que requerido. Ao fim da sessão foi solicitada aos adolescentes, como tarefa de casa, uma pesquisa sobre os custos econômicos de um bebê: deveriam fazer um orçamento de fraldas, comida, roupa de criança etc. (Serrão \& Balleeiro, 1999). Quando indagados sobre a (in)satisfação para com a sessão, um dos relatos de ganho foi refletir sobre quando deve ser o começo da vida sexual ativa: "Não fazer sexo antes do tempo".

A décima segunda sessão pretendeu desenvolver pensamento crítico, tomada de decisão, resolução de problema e enfrentamento ao estresse. Inicialmente os adolescentes foram divididos em subgrupos de quatro pessoas, onde discutiram sobre os custos de se ter um filho. Em seguida os facilitadores retomaram os temas abordados nas sessões anteriores e realizaram uma discussão com a turma. Posteriormente, os facilitadores listaram no quadro frases, emitidas pelo parceiro ou por colegas, que expressavam pressão, risco de coerção sexual ou riscos à saúde. Em seguida, os facilitadores encenaram as situações indicadas pelas frases, sempre cedendo à pressão ao término da encenação e perguntando aos adolescentes se conseguiram localizar 0 problema e quais alternativas utilizariam para resolvêlo. Com as opiniões colhidas, os facilitadores encenaram novamente dando um desfecho adequado e discutindo, posteriormente, com os participantes. Ao fim da sessão, os facilitadores distribuíram aos adolescentes uma lista com os direitos sexuais e reprodutivos e discutiram cada um deles. Nesse ponto do programa, a equipe de pesquisa criou uma comunidade no Orkut sobre o Programa de Habilidades de Vida com o intuito de manter o vínculo com os adolescentes, ampliar as trocas entre eles e utilizar uma linguagem compartilhada pela cultura adolescente (Goldston \& cols., 2008; Harper, 2007). A tarefa de casa consistiu em acessar a comunidade do projeto de pesquisa "Habilidades de Vida" no Orkut e responder ao fórum de discussão. Os relatos de satisfação com a sessão indicam uma reflexão sobre 0 enfrentamento à pressão de pares e parceiros: "O encontro de hoje foi bom, ficou claro que os amigos influenciam, mas é preciso ter consciência", "Não ir pela opinião dos outros".

$\mathrm{Na}$ décima terceira sessão, foi abordada a construção social dos papéis de gênero e a tolerância ao diferente na perspectiva da diversidade sexual. Os adolescentes participaram de uma discussão de uma fábula contida no livro "O abraço da onça e do tamanduá” (Lusz, 2003). A fábula trata de um romance entre uma onça e um tamanduá e aborda a convivência, a amizade e 0 afeto entre bichos diferentes. 0 autor do livro, Pedro Lusz, proferiu uma palestra para os alunos nesse encontro. As diferenças entre os personagens e as estratégias encontradas para lidar com elas foram utilizadas como metáfora para tratar dos diferentes modos de ser homem e de vivenciar a sexualidade. 0 autor falou de sua própria construção de gênero, da cultura machista, dos estereótipos de gênero e da relação entre flexibilidade nos papéis de gênero e a saúde mental masculina.

A décima quinta sessão foi utilizada para se avaliar qualitativamente 0 programa, discutir a prevenção de recaída e encerrar o programa. Os participantes foram solicitados a escrever o que pensavam antes e após 0 programa sobre ser homem (ou ser mulher), homossexualidade, virgindade, aborto, anticoncepção e gravidez na adolescência. Em seguida, foi feita uma exposição dialogada sobre prevenção de recaída. Foram informados que a mudança pode ser acompanhada por recaídas e que estas podem ser úteis para se identificar lacunas nas habilidades de enfrentamento a situações de risco à saúde e/ ou desenvolvimento (ex.: eventualmente, poderiam sucumbir à pressão do parceiro para fazer sexo sem querer por falta de assertividade). A recaída não significa fracasso, mas oportunidade para se conhecer melhor e voltar a se comprometer com a própria mudança ou projeto de vida. Foram instruídos a prever situações de risco interpessoais e planejar formas de evitar entrar em situações de risco ou de sair delas quando for 0 caso. Por fim, para despedida, foi feita a técnica do Amigo Secreto Imaginário (D el Prette \& D el Prette, 2001), em que cada aluno escolhia uma pessoa no grupo e dava a ela um presente simbólico (ex.: a amizade, um elogio ou votos de sucesso). Este, por sua vez, repetia 0 procedimento, até que todos escolhessem alguém e 
fossem escolhidos. Ao final, a equipe agradeceu a participação de todos e encerrou o programa.

\section{Considerações finais}

Os resultados desta experiência, associados à discussão, foram compostos basicamente de dados e reflexões sobre as condições que caracterizaram a intervenção e indicadores de aceitabilidade do programa pelos adolescentes. Esses dados sugerem que, em replicações deste programa, uma melhor aceitabilidade do mesmo pode ser alcançada se for feita uma modificação na ordem das sessões - o terceiro módulo deve ocupar o lugar do primeiro - e se forem priorizadas técnicas interativas, lúdicas e coerentes com a cultura adolescente, tal como destacado em outros estudos sobre prevenção na adolescência (D el Prette \& Del Prette, 2009b; Goldston \& cols., 2008; Harper, 2007) e sobre o uso de recursos interativos em programas de habilidades sociais (Lopes, 2009) e de vida (Minto \& cols., 2006). Sugerem também que a avaliação de satisfação, ao final da sessão, inclua medidas escritas, a fim de facilitar o acesso ao dado para um número maior de participantes, uma vez que nem todos os adolescentes relataram oralmente suas impressões sobre a sessão.

As condições e reflexões efetuadas também permitiram identificar aspectos dificultadores (a serem modificados) e facilitadores (a serem mantidos e maximizados). 0 principal aspecto dificultador do programa parece ter sido o grande número de adolescentes por grupo. Um menor número de integrantes por grupo poderia facilitar a participação dos adolescentes, principalmente em atividades que envolvem o falar em público. Do contrário, técnicas específicas que facilitem o falar em público devem ser feitas. Cuidados semelhantes foram também apontados por Del Prette e Del Prette (2001; 2005). O utra medida recomendada seria a constituição de uma equipe maior de facilitadores (por exemplo, seis por turma), para que atividades em pequenos grupos possam ser feitas e adequadamente monitoradas, tendo um facilitador por subgrupo.

Diferentemente do que tem sido apontado por outros autores (Borges \& Meyer, 2008; Diniz \& Asinelli-Luz, 2007; Nogueira \& cols., 2008), os temas desta intervenção voltados para os direitos sexuais e reprodutivos (como o direito à orientação sexual homossexual), que geram hostilidade e resistência em ambiente escolar, geraram poucas reações desse tipo entre os participantes. 0 módulo que abordou esse tema foi 0 que contou com mais interesse $e$ engajamento por parte dos adolescentes. Estudos futuros devem explorar dimensões contextuais e culturais, tais como nível de instrução dos pais e religião, que podem influenciar na aceitabilidade de intervenções educacionais para promoção de direitos sexuais e reprodutivos.

Quanto aos aspectos facilitadores do programa, pode-se destacar 0 tema da sexualidade, gênero e direitos sexuais e reprodutivos e 0 investimento feito na qualidade da relação facilitador-adolescente. No primeiro aspecto, a aceitabilidade dos adolescentes para com esse módulo da intervenção permite reafirmar a relevância e a adequação de intervenções preventivas com este foco na adolescência. É possível que os adolescentes não disponham de outros ambientes em que possam discutir tais assuntos. Assim, a escola se configuraria como um dos poucos fatores de proteção do adolescente na promoção de sua saúde sexual e reprodutiva. No segundo aspecto, o relato desta experiência indica ser necessário monitorar e estimular 0 vínculo entre facilitador e adolescente. Em um estudo de avaliação de programas em prevenção primária para adolescentes, Sale e cols. (2008) identificaram que as mudanças em habilidades sociais dos participantes eram mediadas pelo vínculo entre adolescentes e facilitador. Assim, a qualidade do vínculo estabelecido parece constituir variável importante no alcance das metas finais do programa.

Conclui-se, portanto, que esta experiência permitiu levantar indícios de que o programa gerou boa aceitabilidade por parte dos adolescentes, sobretudo no módulo relativo a sexualidade, gênero e direitos sexuais e reprodutivos. Além disso, foram constatadas necessidades de ajustes no programa em sua próxima implementação, no que diz respeito à ordem das sessões, à natureza das técnicas de intervenção e avaliação empregadas, ao número de adolescentes por grupo, ao número de facilitadores e ao monitoramento da relação entre facilitadores e adolescentes. Sugere-se que estes dados sejam considerados no planejamento de estudos futuros focados na testagem da eficácia de programas de habilidades interpessoais para promoção da equidade de gênero e de orientação sexual e prevenção a transtornos em saúde sexual e reprodutiva na adolescência.

\section{Referências}

Aldrighi, T. (2004). Prevalência e cronicidade da violência física no namoro entre jovens universitários do Estado de São Paulo - Brasil. Psicdogia: Teria ePrática, 6(1), 105-120.

Andrade, L. H. S. G., Viana, M. C., \& Silveira, C. M. (2006). Epidemiologia dos transtornos psiquiátricos na mulher. Revista de Psiquiatria Clínica, 32(2), 43-54. 
Aquino, E. M. L., Heilborn, M. L., Knauth, D., Bozon, M., Almeida, M. C., A raújo, J., \& Menezes, G. (2003). Adolescência e reprodução no Brasil: a heterogeneidade dos perfis sociais. Cadkmos de SaúdePúdica, 19(2), 377-388.

Asinelli-Luz, A., \& Fernandes Jr., N. (2008). Gênero, adolescências e prevenção ao HIV/AIDS. Pro Posiçes 19(2), 81-91.

Bandeira, L. (2009). Três décadas de resistência feminista contra o sexismo e a violência feminina no Brasil: 1976 a 2006. Sociedade eEstado, Braślia, 24(2), 401-438.

Bolsoni-Silva, A. T., Del Prette, Z. A. P., Del Prette, G., Montagner, A. R., Bandeira, M., \& Del Prette, A. (2006). Habilidades sociais no Brasil: uma análise dos estudos publicados em periódicos. Em M. Bandeira, Z. A. P. Del Prette \& A. Del Prette (O rgs.), Estudos sobre habilidades soiais $\mathrm{e}$ rdadionamento interpesscal (pp. 17-45). São Paulo: Casa do Psicólogo.

Borges, Z. N., \& Meyer, D. E. (2008). Limites e possibilidades de uma ação educativa na redução da vulnerabilidade à violência e à homofobia. Avaliação ePdíticas Públicas emEducação, 16(58), 5976.

Del Prette, A., \& Del Prette, Z. A. P. (2001). Psicloga das racaçés interpesscais vivênias para o trabalho em gupa Petrópolis: Vozes.

Del Prette, A., \& Del Prette, Z. A. P. (2009a). Inventánio de Habilidades Scaiais para Addescentes (IHSA-DdPrette): manual deaplicacãa, apuraçãoeintenpraçãa São Paulo: Casa do Psicólogo.

Del Prette, A., \& Del Prette, Z. A. P. (2009b). Adolescência e fatores de risco: a importância das habilidades sociais educativas. Em V. G. Haase, F. O. Ferreira \& F. J. Penna (O rgs.), Aspetos biopsicossociais da saúde na infânia e addescênia (pp. 503-522). Belo Horizonte: Coopmed.

Del Prette, Z. A. P., \& Del Prette, A. (2005). Habilidadss sociais na infâna: teeria e prática Petrópolis: Vozes.

Del Prette, Z. A. P., \& Del Prette, A. (2006). Sistema miltimáda de habilidades sociais para cianças São Paulo: Casa do Psicólogo.

Dinis, N., \& Asinelli-Luz, A. (2007). Educação sexual na perspectiva histórico-cultural. Educar emReista, (30), 77-87.

Epstein, J. A., Griffin, K. W., \& Botvin, G. J. (2002). Positive impact of competence skills and psychological wellness in protecting inner-city adolescents from alcohol use. Preention Säense 3(2), 95-104.

Goldston, D. B., Molock, S. D., Whitbeck, L. B., Murakami, J. L., Zayas, L. H., \& Hall, G. C. N. (2008). Cultural considerations in adolescent suicide prevention and psychosocial treatment. Ameican Psychdogst, 63(1), 14-31.

Gresham, F. S. (2009). Análise do comportamento aplicada às habilidades sociais. Em Z. A. P. Del Prette \& A. Del Prette (Orgs.), Psicloga das habilidades soiais diversidadeténica eimplicaçães práticas (pp. 17-66). Vozes: Petrópolis.

Harper, G. W . (2007). Sex isn't that simple: culture and context in HIV prevention interventions for gay and bisexual male adolescents. American Psydhogist, 87, 806-819.

Junqueira, R. D. (Org.). (2009). Divesidade sexual na eduraçãa prodematizaçés sdare a homfdia nas esclas Brasília: Ministério da Educação, Secretaria de Educação Continuada, Alfabetização e Diversidade; O rganização das Nações Unidas para a Educação, a Ciência e a Cultura.

Lima, D. C., Büchele, F., \& Clímaco, D. A. (2008). Homens, gênero e violência contra a mulher. Saúde eScicelade, 17(49), 69-81.

Lionço, T., \& Diniz, D. (2009). Qual a diversidade sexual dos livros didáticos brasileiros. Em T. Lionço \& D. Diniz (O rgs.), Homfdabia eeduraçãa um desafio ao silênio (pp. 9-14). Brasília: Letras Livres. EdUnB.

Lopes, D. C. (2009). Reursos miltimídia na promyão de habilidades soiais com vianças com difiauldades de aprendizagem (Dissertação de Mestrado). Universidade Federal de São Carlos, São Carlos, São Paulo, Brasil.

Louro, G. L. (2007). Pedagogias da sexualidade. Em G. L. Louro (O rg.), O coppo eclurada peelaggajas da sexualidade(pp. 7-34). Belo Horizonte: Autêntica.

Lusz, P. (2003). O abraço da onça edb tamanduá G oiânia: Porã Cultural.

Lynch, K. B., Geller, S. R., \& Schmidt, M. G. (2004). Multi-year evaluation of the effectiveness of a resilience-based prevention program for young children. The Joumal of Primary Prevention, 24(3), 335-353.

Matos, M., Machado, C., Caridade, S., \& Silva, M. J. (2006). Prevenção da violência nas relações de 
namoro: intervenção com jovens em contexto escolar. Psicdoja: Tøria ePrática, 8(1), 55-75.

Mattar, L. D. (2008). Reconhecimento jurídico dos direitos sexuais: uma análise comparativa com os direitos reprodutivos. SUR. Reista Intemaional de Direitos Humanos, 5(8), 60-83.

Ministério da Saúde (2004). Programa Brasil sam Homfdia: programa de combate à vidênia e discriminação contra GLBT e de promyão da didadania homosexual. Brasília: Ministério da Saúde. Conselho Nacional de Combate à Discriminação.

Minto, E. C., Pedro, C. P., Cunha Netto, J. R., Bugliani, M. A. P., \& Gorayeb, R. (2006). Ensino de habilidades de vida na escola: uma experiência com adolescentes. Psicdoja em Estudb, 11(3), 561568.

Munoz, R. F., Mrazek, P. J., \& Haggerty, R. J. (1996). Institute of Medicine report on prevention of mental disorders: summary and commentary. American Psychdogist, 51(11), 1116-1122.

Murta, S. G. (2007). Programas de prevenção a problemas emocionais e comportamentais em crianças e adolescentes: lições de três décadas de pesquisa. Psicdoga: RellexãoeCńtica, 20(1), 4-11.

Murta, S. G, (2008). Programa de habilidades devida para addescentes manual para aplicadores Goiânia: Porã Cultural.

Murta, S. G., Borges, F. A., Ribeiro, D. C., Rocha, E. P., Menezes, J. C. L., \& Prado, M. M. (2009). Prevenção primária em saúde na adolescência: avaliação de um programa de habilidades de vida. EstudosdePsicdoga, Natal, 14(3), 181-189.

Murta, S. G., Del Prette, A., \& Del Prette, Z. A. P. (2010). Prevenção ao sexismo e ao heterossexismo entre adolescentes: contribuições do treinamento em habilidades de vida e habilidades sociais. Revista dePsicdoja da Criança edoAddescante(Lisboa), 2, 7386.

Nogueira, C., Saavedra, L., \& Costa, C. (2008). (In)Visibilidade do gênero na sexualidade juvenil: propostas para uma nova concepção sobre a educação sexual e a prevenção de comportamentos sexuais de risco. ProPosiç̃es 19(2), 59-79.

Pocahy, F. A., \& Nardi, H. C. (2007). Saindo do armário e entrando em cena: juventudes, sexualidades e vulnerabilidade social. Estudbs Feministas 15(1), 45-66.

Ribeiro, P. R. C., \& Quadrado, R. P. (Orgs.). (2008). Coppos, gêneo e sexualidades questões posśvies para o amíauloescdar. Rio G rande: Editora da FURG.

Sale, E., Bellamy, N., Springer, J. F., \& Wang, M. O. (2008). Quality of provider-participant relationships and enhancement of adolescent social skills. The Jaumal of Primary Prevention, 29(3), 263-278.

Schraiber, L. B., D’Oliveira, A. F. P. L., \& França Jr., I. (2005). Violência sexual por parceiro íntimo entre homens e mulheres no Brasil urbano. Rexista de SaúdePública, 42(1), 127-137.

Schwartz, J. P., Magee, M. M., Griffin, L. D., \& Dupuis, C. W. (2004). Effects of a group preventive intervention on risk and protective factors related to dating violence. Group Dynamis Thery, ReserenchandPractice 8(3), 221-231.

Secretaria Especial de Políticas para as Mulheres (2005). Plano Nadional de Pdíticas para as Mulheres Brasília: Presidência da República/ Secretaria Especial de Políticas para as Mulheres.

Serrão, M., \& Baleeiro, M. C. (1999). Aprendendba ser ea conviver. São Paulo: FTD.

World Health Organization (1997). Life skills eluration for dildren and addescents in shods Geneva: Programme on Mental Health World Health Organization.
Reedidoem16/ 02/ 2011 Refomiladoem23/ 08/ 2011 Aprovadoem23/ 08/ 2011

Este trabalho foi desenvolvido durante o estágio de Pós-Doutorado (Bolsa CNPq, Processo 150091/2009-5), realizado pela primeira autora junto ao Grupo de Pesquisa coordenado pelos dois últimos autores (http:/ / www.rihs.ufscar.br).

Apoio: Conselho Nacional de Desenvolvimento Científico e Tecnológico - CNPq (Edital Saúde da Mulher, Processo 551319/2007-0). 
Sobre os autores:

Sheila Giardini Murta é professora adjunta vinculada ao Departamento de Psicologia Clínica e ao Programa de Pós-Graduação em Psicologia Clínica e Cultura da Universidade de Brasília.

Danilo Cruvinel Ribeiro é psicólogo graduado pela Pontifícia Universidade Católica de Goiás.

Isabela de Oliveira Rosa é mestranda no Programa de Pós-Graduação em Psicologia Social e do Trabalho da Universidade de Brasília.

Jordana Calil Lopes de Menezes é mestranda no Programa de Pós-Graduação em Psicologia Clínica e Cultura da Universidade de Brasília.

Marcella Regina Silva Rieiro é psicóloga graduado pela Pontifícia Universidade Católica de Goiás.

Ohary de Sousa Borges é enfermeiro graduado pela Pontifícia Universidade Católica de Goiás.

Silvia Guimarães de Paulo é psicóloga graduado pela Pontifícia Universidade Católica de G oiás.

Verônica de O liveira é psicóloga graduado pela Pontifícia Universidade Católica de Goiás.

Victor Hugo de Miranda é psicólogo graduado pela Pontifícia Universidade Católica de G oiás.

Almir Del Prette é professor titular vinculado ao Programa de Pós-Graduação em Psicologia e em Educação Especial da Universidade Federal de São Carlos.

Zilda A. P. Del Prette é professora titular vinculada ao Programa de Pós-Graduação em Psicologia e em Educação Especial da Universidade Federal de São Carlos.

Contato com os autores:

Departamento de Psicologia Clínica, Instituto de Psicologia, Universidade de Brasília, Campus Darcy Ribeiro, Brasília, DF, CEP 70910-900.

Email: murta@ cultura.com.br; giardini@unb.br 